\title{
EL EJERCICIO DE LA DEMOCRACIA EN LAS ORGANIZACIONES DE PARTICIPACIÓN DE PRODUCCIÓN: LA ADMINISTRACIÓN DE JUSTICIA
}

\author{
POR \\ Carlos GARCÍA-GUTIÉRREZ FERNÁNDEZ ${ }^{1}$
}

\section{RESUMEN}

Se ha conocido que la democracia se ha visto trastocada, tergiversada, amputada. Se tiene constancia de que los sistemas políticos convencionales son sólo aparentemente democráticos. Y, gracias a la disponibilidad de participar en los flujos de información en el ámbito de la sociedad es posible atisbar el derrumbe de las instituciones que se han revelado como abusadoras de poder, ladronas de la democracia. Se vislumbra la instauración de otros sistemas mejor adaptados a la situación más reciente.

En la vida económica, también hay abusos de autoridad, de poder y hay tergiversaciones. La democracia queda circunscrita $y$, con muchas limitaciones, al establecimiento de los objetivos.

Adicionalmente, hay un objetivo sobre la que hay un consenso implícito por parte de todos los participantes, sea cual sea el tipo de organización: incrementar el valor de la organización; con lo que se consigue atender a los objetivos de todos los intervinientes, la aplicación de la regla una persona un voto no es necesario. Incluso puede ser contraproducente, al menos, coyunturalmente, mientras que unos y otros son conscientes de ese beneplácito. De manera que hasta que se llega a esa situación, de forma inducida, se pueden producir conflictos que conviertan en un juego de suma negativa la participación de unos y de otros.

\footnotetext{
${ }^{1}$ Universidad Complutense de Madrid. Dirección de correo electrónico: cggf@msn.com

REVESCO No 112 - Extraordinario en Homenaje al Profesor Alfonso Carlos MORALES

GUTIÉRREZ - ISSN: 1885-8031 - www.ucm.es/info/revesco

http://dx.doi.org/10.5209/rev_REVE.2013.v112.43067

Fecha de recepción: 31/07/2013

Fecha de aceptación: 20/09/2013
} 
Siendo pequeño el margen de maniobra para la toma de decisiones de manera democrática y siendo necesaria la restitución de derechos, las organizaciones se pueden dotar de sistemas de administración de justicia al margen de los convencionales, con las debidas garantías, para recomponer el sentido amplio de la democracia que alcanza también a la justicia, y es particularmente relevante en el ámbito de las organizaciones de producción, y más aún, en las de producción de participación.

Palabras clave: Autoridad, Competencia, Cooperación, Eficiencia, Justicia, Naturaleza

Claves ECONLIT: L260, J540, M130

\title{
THE PURSUIT OF DEMOCRACY IN THE PRODUCTION SHARING ORGANIZATIONS: ADMINISTRATION OF JUSTICE
}

\begin{abstract}
It has been known that democracy has been disrupted, distorted, amputated. There is evidence that conventional political systems are only apparently democratic. And, by the way of the availability to participate in the flows of information in the field of society can be glimpsed the institutions collapse that have been revealed as power abusers, democracy thieves. It envisions the establishment of other systems better adapted to the latest situation.
\end{abstract}

In economic life, there are also abuses of authority, of power and no misrepresentations. Democracy is circumscribed and, with many limitations, the establishment of objectives.

Additionally, as there is an objective on which there is an implicit consensus by all participants, regardless of the type of organization: increasing the value of the organization which is achieved to meet the objectives of all involved, the application of one person one vote rule is not necessary. It may even be counterproductive, at least circumstantially, while both are aware of that pleasure. So until you get to that situation, so induced, conflicts can occur that turn into a negative-sum game involving one or the other.

Still little room for democratic decision making and still required the restoration of rights, organizations can provide themselves justice systems outside of conventional ones, with appropriate safeguards, to restore the broad sense of democracy also reaching justice, 
and are particularly relevant in the field of production organizations, and even more in the participation ones.

Keywords: authority, competition, cooperation, efficiency, justice, nature

\section{LA ORGANIZACIÓN DE PRODUCCIÓN Y SUS OBJETIVOS}

Por organización hay que entender aquél grupo de personas que están convocados -e identificados- por un objetivo, que es el que la caracteriza y, lo que es más importante, la identifica. Por ejemplo, el Opus Dei, la Unión General de Trabajadores o Iberdrola son tres organizaciones claramente distintas (y distantes) precisamente, concretamente, específicamente, por sus objetivos.

Se trata de una estructura de poder para establecer los objetivos, lo que la caracteriza. No obstante, eso no quiere decir que la legitimación de sus miembros para establecer los objetivos y para participar en el proceso que trata de conseguirlos sea la misma.

Cuando la legitimación es análoga a la que está presente en la vida civil, la de los ciudadanos: una persona un voto, se puede afirmar que la organización es democrática. Y, para que eso sea así se ha de poder aplicar la analogía a lo que ocurre en la vida civil, en la que ese criterio, generalmente aceptado de participación en la toma de decisiones (al menos para establecer los objetivos) se apoya en la condición de ciudadano o participante en la vida civil. Es decir, en el caso de la organización de producción, ha de ser, además, de participación.

\subsection{Definición de organización de producción de participación}

Una organización de producción de participación es una unidad cuya función, la que la caracteriza, es la producción y distribución de bienes y servicios con base en las decisiones de los socios, que lo son por su condición de proveedores de algún factor de producción real (bien o servicio) o de consumidores de alguno de los productos (bien o servicio). independiente de su posición financiera sobre la organización y, por tanto, de la forma jurídica con la que se disfraza. 
En consecuencia, por analogía, la democracia, el sistema de participación en la toma de decisiones de la vida civil, sería de aplicación a la vida económica, con base en las mismas consideraciones: la condición de socio como si de un ciudadano de la organización se tratara.

\subsection{Los miembros de la organización}

Esto lleva a la consideración de miembro de la organización, que ha de ser sencilla, clara y terminante: sin ambigüedades. Aquí se propone una que sea delimitadora. No valen las imprecisiones que se proponen por algunos. Por ejemplo, como esas que dicen que en ese tipo particular de organización que es la unidad de producción y distribución de bienes y servicios hay muchos grupos interesados(sic) o que tienen intereses:

- los trabajadores (muchos no especifican si se trata de asalariados o no -esta indeterminación es interesadamente ambigüa en el caso del Derecho de Trabajo aunque habría que decir de los asalariados-),

- los ejecutivos (que son un tipo particular de trabajadores) que acumulan poder en su propio beneficio: como todos, pero éstos, de manera particular disponiendo de un porcentaje de información de su situación en la estructura administrativa),

- los capitalistas,

- los acreedores (aquí se incluyen a los banqueros que representan a algunas entidades de crédito y a otras de descrédito)

- los proveedores de bienes y servicios

- los sindicatos y las centrales sindicales (que, sin ser representativos, se "meten en camisas de once varas" como una estrategia de supervivencia), la "patronal (identificada con un término histórico ¿antediluviano? por algunos periodistas que no conocen bien y escriben "de oídas" la estructura empresarial real),

- los clientes,

- los consumidores, 
- los poderes públicos (abusadores, en muchos casos, de su ejercicio, configurando lo que se conoce como corrupción: mordidas, sobres, astillas, etcétera) en sus diferentes manifestaciones según los ámbitos local, municipal, autonómico, federal, confederal, nacional, comunitario (léase supranacional),

Evidentemente, en esta larga nómina de participantes, la participación se basa casi exclusivamente en el saqueo (buscando la analogía con la naturaleza): en la apropiación de la mayor parte posible del pastel creado y generado por la organización de la que son partícipes más o menos tangencialmente. Ahora bien, así como los depredadores en la naturaleza son conservacionistas (sólo matan lo que necesitan para sobrevivir), así debe ocurrir con los participantes en la organización que buscan la eficiencia en su función procurando "no matar a la gallina de los huevos de oro".

Abundando: los participante de una organización de producción de participación son sólo los miembros que están involucrados, como pasa con los cerdos en la tortilla de jamón mientras que las gallinas sólo están comprometidas; y, como ocurre con muchos de esa relación, sólo están interesados en recibir el peaje (por ejemplo los sobres a través de los tesoreros de algunos partidos políticos, o los impuestos, o retribuciones en especia) para que los políticos (del tipo que sean) las dejen seguir viviendo e incluso les den "cuartelillo" cuando está en su mano porque tienen competencias de gobierno.

Nótese, dicho sea de paso, lo tergiversado que está en el mercado por los "administradores" públicos que han confundido, interesadamente, la intervención del sector público en la economía propuesta por John Maynard KEYNES con la restitución de los peajes medievales.

Se entiende por miembro de la organización a la persona física que participa en el establecimiento de los objetivos. En efecto, ya que no cabe hablar de democracia -que es una de las preocupaciones anunciadas en el título- si se mezclan personas humanas, como dicen algunos, con otro tipo de personas. Y esto lleva a la consideración de cómo, de qué manera, se establecen los objetivos entre los miembros, personas físicas.

Este punto es crucial porque está íntimamente ligado al poder y a lo que legitima la capacidad para establecer los objetivos, el poder de tomar decisiones, para identificar que es lo que caracteriza a una determinada organización. 


\subsubsection{Ejemplos ilustrativos}

Algún ejemplo pueden ayudar a aclarar algunos conceptos.

En un despacho de abogados (en plural: huyendo de esas contradicciones en los términos que son, entre otras, las sociedades unipersonales) los objetivos los establecen los socios: los abogados que, posiblemente, son una agrupación basada en la complementariedad -buscando unas mejor posición entre los competidores- de sus capacidades profesionales para que el resultado del conjunto sea mejor para todos y cada uno de ellos que si desarrollaran su actividad profesional por separado; en el bien entendido que todo tienes sus ventajas e inconvenientes (entre otras cosas porque "más vale sólo que mal acompañado" y porque "el buey sólo bien se lame").

Este ejemplo es adaptable a muchas otras situaciones: se puede pensar en un partido político (en los que abundan los licenciados en derecho); en un taller de automóviles, en una consultora de esas que está especializada en la confección de cualquier tipo de informe porque la base de su negocio son los vínculos con los políticos; en un estudio de arquitectos; etcétera.

En efecto, los abogados, personas físicas, reunidos, asociados, socios en suma, son los que establecen los objetivos de la sociedad, y, evidentemente, deben ser de tal naturaleza que no sean inconvenientes (sino todo lo contrario) con sus objetivos personales. Sin embargo, la mecánica para llegar a establecer esos objetivos de la sociedad puede basarse, en este ejemplo en, al menos, tres elementos:

1. El montante del valor de las aportaciones que forman el capital que configura a efectos de terceros a la sociedad como persona jurídica, en el caso de que el despacho se presente al exterior como una sociedad mercantil (en terminología del Derecho Mercantil).

2. El prestigio profesional, la ascendencia ante los tribunales, el mayor oficio o el tirón comercial de algún o algunos socios, a los que se les atribuye mayor ascendencia, capacidad y resultados, generalmente, explicada por su maestría, capacidad y, además, por su experiencia y antigüedad en el oficio (“más sabe el diablo por viejo que por diablo").

3. Ambos (que, en muchos casos, están correlacionados). 
De cualquier manera, además, hay que tener en cuenta el propio desarrollo del proceso productivo y de distribución (en este caso, el ejercicio profesional) que está condicionado por restricciones técnicas y tecnológicas, de aplicación de métodos, de presencia de la competencia, de relaciones institucionales, de marco legal, etcétera. Es decir, que las manos no son libres del todo.

Esos son los mimbres para estar en condiciones de establecer los objetivos, que es un proceso esencial para caracterizar a la organización; y una de las opciones es que ese proceso se desarrolle democráticamente: una persona (física, por supuesto; o bien humana como dicen algunos) un voto.

\subsection{El fin, los objetivos y las metas}

El castellano es un idioma poderoso (el segundo por número de hablantes en el mundo según refieren las estadísticas) con un vocabulario muy rico y extenso que le confiere a las palabras que son sinónimas una determinada jerarquía.

Así, en este caso, conscientes de que el lector conoce perfectamente el significado de términos que forman parte del título de este sub - epígrafe, es posible afirmar que es preciso alcanzar varias metas para haber conseguido un determinado objetivo; y haber alcanzado varios objetivos para alcanzar el fin de la organización.

Más concretamente, el fin de cualquier ser vivo es la supervivencia, que es aplicable a cualquier organización.

A ese fin tratan de referirse incluso organizaciones mortecinas, prácticamente agotadas que nacieron para cumplir un papel concreto en épocas recientes de la historia de la civilización en las que la confrontación de los factores de producción generaba conflictos que devenían en tensiones y acuerdos, pero que se han convertido en lastres para la vida socioeconómica porque los saldos son negativos; y es que "a todo cerdo le llega su San Martín”.

En el caso de la organización de producción, en general, y de la organización de producción de participación, en particular, es posible, como si se tratara de un ser vivo, plantear un solo objetivo: hacer máximo su valor (más concretamente, que de periodo en periodo se incremente o, al menos que no decrezca), con lo que, en definitiva, se contribuye al 
fin de la organización que es la supervivencia; y para conseguirlo hay que alcanzar un abanico de subobjetivos en los distintos ámbitos de la organización: el comercial, el productivo, el financiero, el tecnológico.

Finalmente, para alcanzar cada uno de esos subjetivos (la lista puede ser exhaustiva, e incluso susceptible de aplicarle una jerarquía y de distribuirla en un árbol, con dimensión temporal, de causas y efectos) es necesario lograr determinadas metas, que es la expresión más operativa y concreta sobre la que apoyarse para avanzar.

\subsubsection{El valor de la organización}

Este parámetro resulta la quintaesencia de lo expuesto más arriba. En efecto, cualquier miembro de cualquier organización ve sus objetivos alcanzados si la organización consigue que su valor no se reduzca. Es más, si se mantiene, mejor aún; y si se incrementa: “¡miel sobre hojuelas!".

No se quiere entrar aquí a discernir sobre lo complejo y difícil de conocer el valor de una organización de seres humanos que producen y distribuyen bienes y servicios, y más aún si es de participación, porque eso trasciende los objetivos que se pretenden y porque, aunque es muy importante, sería prolijo.

Sin embargo, si se puede afirmar que esa coincidencia referida mas arriba y el encadenamiento de decisiones permite concluir que la democracia en las organizaciones de producción de participación, en particular, y de producción, en general, está sobreentendida y, por tanto, no es necesaria ejercerla. Aunque eso no es óbice para que se perfeccionen (simplifiquen, aligeren, reduzcan) los órganos de manifestación de la "soberanía popular" y que desarrollen sus funciones con pulcritud y exquisitez.

\subsection{La responsabilidad de los miembros}

La responsabilidad: la capacidad de asumir las consecuencias de las decisiones es la base de esa democracia no ejercida, y, por supuesto, un sistema de evaluación de contraprestaciones que sea justo, y, por tanto, estimulante.

En realidad la democracia en la organización como se trata de argumentar queda circunscrita al ejercicio de la responsabilidad de los participantes con la organización que 
pueden, en el ejercicio de su libertad, hacer un juego limpio, o, alternativamente, tratar de sacar más provecho del valor de lo que aportan, abusando de las aportaciones de los otros miembros.

\subsection{La justicia en la organización}

En efecto, como pasa con la vida política en la que la justicia, que pretende garantizar la compensación de las decisiones (dar a cada uno lo suyo), lo que es más urgente en la organización de participación es disponer de un sistema judicial propio, interno, independiente, el que nadie esté privilegiado y que sea eficiente: que la aplique de manera indiscutida, concerniente con el entorno y con el sentido común; y, además, sin cortapisas, con autoridad y con capacidad de que sus resoluciones sean ejecutadas sin ambigüedad.

Las normas son las del sentido común, y, como se hace tantas veces en el mundo jurídico, pero también en cualquier ámbito, se aplica la analogía para las compensaciones. Evidentemente, en una organización no puede haber capacidad sancionadora de restricción de libertad, sino de reclamación pecuniaria de daños y perjuicios: que el valor que ha podido ser robado, malversado, defraudado o estafado sea restaurado y devuelto a los legítimos propietarios.

Para este caso, para reclamar la compensación de los eventuales abusos en todos los órdenes (retributivo, por exclusión, por marginación, desatención, etcétera) es necesario que las organizaciones, como si de un estado de derecho se tratara, se doten de mecanismos de reclamación de la justicia, en un ámbito interno, con la autonomía con la que tienen derecho a regularse tanto más legítima cuanto más amplio sea su ámbito geográfico de actividad, con capacidad suficiente como para poder exigirla sin necesidad de acudir a la autotutela (que es ilegal), pero tan independientes como sea posible del injusto, por lento e ineficiente, poder judicial (valga la redundancia).

Restituir los derechos y retribuciones que puedan haber sido conculcados es, por un lado, un acto de justicia, pero, además, una necesidad para los miembros responsables de una organización que quieran seguir contando con los miembros eficientes.

En consecuencia, el establecimiento de un sistema de resolución de conflictos mediante un jurado interno, con una rotación suficiente y adecuadamente diseñada, y la aplicación de sistemas que permitan, en el mejor de los casos, transigir a los eventuales 
integrantes en conflicto, o acudir a un árbitro, si el primer sistema no se revelara adecuado, tendrían en cuenta el ejercicio de una justicia con la que se conforma la democracia como sistema de gobierno.

Evidentemente, la aplicación de la regla una persona un voto debería ser la que se tuviese en cuenta para aprobar el sistema de administración de justicia interno, que, por tanto, estaría sometido a actualizaciones dependiendo de la voluntad democráticamente manifestada de los integrantes de la organización en cada momento, sin que ello suponga arbitrariedad.

En realidad, esta propuesta es de aplicación -y está regulada- en algún tipo de empresas democráticas para las que la incorporación de los miembros conlleva la asunción de unos compromisos basados en el sentido común y en la buena fe; y están recogidos en la norma interna de la empresa.

\section{LA DEMOCRACIA NO ES NATURAL: NO ESTÁ EN LA NATURALEZA}

En la naturaleza se impone el principio de la supervivencia, que tienen tanta fuerza que es lo que explica el comportamiento de todo lo que la compone.

Entre las diferentes organizaciones de seres vivos que hay en la naturaleza no se encuentra ninguna en la que la democracia se ejerza de manera formal, y, mucho menos informal. Siempre se aplican procesos de adaptación.

Para simplificar, haciendo un análisis comparativo es conveniente fijarse en los mamíferos que son más próximos a los seres humanos: orangutanes y bonobos, con los que tenemos tantísimas coincidencias en el ADN. Pero esta comparación puede alcanzar a cualquier elemento: incluso en el ámbito de las partículas subatómicas el comportamiento es análogo: las diferentes fuerzas de la naturaleza se manifiestan y los elementos buscan equilibrios.

El comportamiento de las diferentes especies de seres vivos es sencillo y, por tanto, asumible, por la especie de los seres humanos, y por las diferentes organizaciones que crean para atender fines instrumentales. Todas las formas de organización buscan la supervivencia de la especie correspondiente. 
En cualquier caso, sea cual sea la especie que se analice, la supervivencia (el fin por definición) está limitado por las circunstancias y leyes que imperativamente determinan la supervivencia de cada uno de sus integrantes. Condicionamientos interiores y externos de naturaleza orgánica, que, precisamente son los que, adicionalmente, les confieren potencialidades y capacidades competitivas genuinas y diferenciadas.

Así pues, el ejercicio de la democracia, la toma de decisiones aplicando la regla de, un individuo un voto, no es aplicable: las leyes de la naturaleza se imponen al libre albedrío, sin que esto signifique asumir que las cosas están predeterminadas. En efecto, el estado de salud y la suerte (el azar) son elementos esenciales para explicar el devenir de muchos seres vivos según la capacidad con la que han aprovechado y administrado esos dos elementos.

Hay individuos dominantes y otros subrogados, hay individuos con más capacidad de adaptación y otros más frágiles; y, para todos ellos, la irrebatida teoría de la evolución enunciada por Charles DARWIN, como sucesión de adaptaciones al entorno cambiante: una manada de toros, un despacho de abogados (dicho sea de paso), una concentración de corales, etcétera, por la que sobreviven los más aptos, es aplicable.

Así pues, aunque en la especie humana se ha evolucionado mucho, muchísimo, en ese proceso tan poco natural, tan artificial, que es la civilización gracias a la capacidad superior de comunicación, el mantenimiento de la condición de mamíferos carnívoros (animales a los que les es de aplicación, la teoría de la evolución ) que no podemos dejar de ser, limita el ejercicio de la democracia.

\subsection{La cooperación y la competencia}

En la naturaleza se encuentran con mucha facilidad comportamientos contradictorios, pero muy sabios, por su eficacia, para la consecución de la supervivencia.

No sólo hay fenómenos de competencia (a veces hasta la muerte del contrincante), sino que muchos comportamientos son de cooperación entre miembros de la misma especie e incluso de diferentes especies, animados e inanimados. Los casos son tan frecuentes que es preferible no citar ninguno.

Cabe encontrar en estos fenómenos naturales de cooperación la base de lo que son los procesos de producción de bienes y servicios. 
Por ejemplo, cualquier proceso de producción agraria, y más concretamente, las patatas gallegas que son ingrediente sustancial de las extraordinarias tortillas de patatas (o españolas), se producen con el concurso y la cooperación de elementos de diferentes especies de diferente naturaleza.

La cooperación (en mutuo beneficio) de los peces que nadan muy próximos a los tiburones para alimentarse de los seres vivos que se adhieren a su epidermis, o de los pájaros que se alimentan de los insectos que torturan a los hipopótamos son algunas de las manifestaciones de la naturaleza en las que la democracia no existe.

Se trata de pactos naturales que les merece la pena (vale decir que les compensa) a los intervinientes.

La cantidad enorme de fenómenos de la naturaleza en la que los sistemas de decisión no son democráticos es tan grande que no es necesario aludir a ninguno porque la evidencia se impone.

\subsection{La democracia es el menos malo de los sistemas para los seres humanos}

Así pues, se ha de ser consciente de que habida cuenta el peso que representamos los seres humanos en la Tierra, y lo que pesa la Tierra en la Vía Láctea, y lo que representa ésta en el Universo, el asunto de la democracia es poco relevante.

Sin embargo, como la democracia parte de la base de la igualdad de los seres humanos, los unos respecto de los otros, independientemente de su origen, educación, posesiones y circunstancias, al ser un proceso tan trasgresor de la naturaleza, merece la pena insistir, reflexionar y profundizar por la trascendencia y por la capacidad de transgredir el orden natural de las cosas.

\subsubsection{Las estructuras políticas y las reglamentaciones económicas}

En el ámbito de lo público se imponen las leyes (esos ordenamientos que contienen algunas -a veces muchas- mentiras codificadas) como referencias de comportamiento.

En el ámbito económico se impone las reglas contradictorias de la cooperación y la competencia, que se suceden según las circunstancias y la fuerza de los protagonistas. 
Es más, se conoce que los protagonistas económicos se valen de todo (como en el amor y en la guerra) y se comprueba como algunos sistemas políticos, supuestamente democráticos, están "invadidos" y tergiversados por los intereses económicos. Una buena prueba son las fotos que interesa que sean difundidas de las reuniones entre los presidentes de los consejos de administración de las empresas más grandes, financiadoras, más o menos legalmente, de los partidos políticos con expectativas de gobernar, y sus "empleados" externos representados por el presidente del Consejo de Ministros.

No es que haya un "adelgazamiento" -valga la expresión- del sector público que se sirve de empresas vinculadas para desarrollar las funciones propias de la administración pública (por ejemplo: estudios de ingenieros que elaboran los informes que podrían hacer los ingenieros que, por oposición, ocupan puestos de la plantilla del ministerio que encarga el estudio; empresas de seguridad privada -creadas por policías en excedencia- que se encargan de la seguridad de instalaciones militares en las que hay soldados-; y en general, otros negocios carroñeros porque no compiten en el mercado, sino que tienen "patente de corso" amparada en algún tipo de concesión); sino que las empresas más grandes, cooperando y compitiendo, utilizan a la administración pública para adulterar las reglas de mercado con normas, decretos y reglas contradictorias, complejas y manifiestamente mejorables.

Esto es una pauta en los estados (sea como sea como estén representados: monarquía o república) con mucha administración pública; y es algo natural en naciones (como institución que representa al estado) en las que el estado pesa poco ya sea porque tienen poca historia o porque ya ha entrado en la etapa de reducción del sector público.

Nótese que el vocablo sector es incorrecto porque implica, implícitamente, una capacidad de comparar, en este caso, lo público con lo privado; y esto es, evidentemente, imposible.

Incluso se viene asistiendo a un deterioro irreversible de los sistemas políticos en un mundo caracterizado por la disponibilidad generalizada de información que ha permitido comprobar lo que ya se sabía pero no estaba confirmado las ineficiencias de las administraciones públicas y el deterioro irreversible de las instituciones. 


\subsubsection{La justicia para la vigilancia del ejercicio de la democracia}

Sea cual sea el sistema de gobierno, desde que se promulga la separación de poderes que se contrarrestan para evitar la acumulación- la justicia es esencial, central y fundamental. No cabe un sistema político que pretenda ser democrático en el que se asumen, como algo natural, privilegios del tipo,

- por un lado, de in-imputabilidad que llevan a conocidos abusos de poder y a que otros, acaben considerándose impunes;

- por otro lado, aforamientos o, peor aún, indultos.

Aunque la sabiduría popular establece que 1) "Más vale honra sin barcos que barcos sin honra" y que 2) "nobleza obliga", en realidad no siempre se cumple esta hipotética costumbre como fuente del derecho que proponía Hans KELSEN en su Teoría pura de Derecho. Más bien al contrario como se confirma cuando "no salen las cuentas" al evaluar patrimonios acumulados - de valores estimados que circulan por la Red- a lo largo de una vida de servicio y compararlos (incluso "la mitad de la mitad") con la suma de rentas de trabajo del servidor o empleado público en cuestión ni siquiera bajo la hipótesis de que el susodicho hubiera ahorrado toda su renta de trabajo (publicada en el BOE) y lo hubiera ido capitalizando a un tipo de interés generoso de manera acumulativa. "Lo que no son cuentas son cuentos".

"El poder tiende a corromper, y el poder absoluto corrompe absolutamente" (John Emerich EDWARD) Efectivamente, los ciudadanos -que no somos súbditos-, somos sistemáticamente ultrajados. El estado de derecho ha sido subvertido de manera irreversible.

Estamos asistiendo a un cambio de época. Se ha puesto blanco sobre negro (en los medios electrónicos e incluso en la prensa escrita) que hay corrupción en las instancias más ¿altas? (eso que se intitula como "las más altas magistraturas" aunque allá no haya maestros sino otros sustantivos); entre los políticos de diferentes partidos: autonómicos y nacionales.

Los políticos (casi todos los políticos, cada uno en su ámbito): guiados por la avaricia y la corta visión de futuro han desvalijado las cajas de ahorro (que antes se apellidaban "y Montes de Piedad") con la excusa de acceder a la condición de banquero (que, como se sabe, tiene su origen en el negocio de la administración de la usura) para defender el bien común; han recalificado los terrenos en su propio beneficio; han afectado sobremanera el medio 
ambiente; han arramblado con todo, han subvertido las reglas de mercado; e incluso han sido incoherente a los idearios que los caracterizan: ha primado la regla de "todo -lo de hoy y lo de mañana- para mi”. No se han comportado como los animales, con naturalidad, porque la avaricia no es natural, sino que es un pecado -poco inteligente por cortoplacista, como la vida de un ser humano- exclusivo de los seres humanos.

Lo malo de esta situación es que nadie tiene la culpa. No hay responsables. La justicia no ha cumplido su función trascendental de "dar a cada uno lo suyo".

Se sabe que algunos miembros de los sindicatos han metido la mano en el saco del dinero público (que es de todos y no como decía aquella inculta, ordinaria y soez política que afirmaba que "no es de nadie"); algunos banqueros roban, algunas empresas compran favores, algunos periodistas dicen verdades a medias, ....

Y también se conoce que la justicia no aplica las consecuencias del incumplimiento de la normativa, y, sobre todo, el sentido común. No hay justicia; y, por tanto, no hay democracia.

\subsubsection{SI NO HAY JUSTICIA NO HAY DEMOCRACIA}

La justicia es lo que importa. No vale el argumento del "coste político" ¿perdida de prestigio profesional?, se trata de que "el que la hace la pague" y "que cada palo aguante su vela".

Lo que sigue es una lista numerada de problemas suficientemente conocidos de la justicia que la configuran más como un problema que como una solución. Si la justicia funcionara bien no habría corrupción y la administración pública estaría al servicio de la sociedad y no al revés. Aquí, por tanto, es aplicable el viejo aforismo latino: "El que es causa de la causa es causa del mal causado"

1) Se ha creado -hace tiempo, con base en la revisable Constitución- el incorrectamente denominado Tribunal Constitucional (que no forma parte de la pirámide de los Tribunales de Justicia), que se encaraman por encima del Tribunal Supremo aunque no todos sus miembros lo son del poder judicial. Es decir, se confunde, y no sólo por el abuso del lenguaje, lo político con lo judicial. 
2) Se han conocido casos en los que se tergiversa la propia administración de justicia. No sólo por el incumplimiento de su función de los fiscales, que no actúan de oficio o, si lo hacen, no cumplen con la función para la que está creado, para actuar a favor del estado como si de "abogados del estado" (vale decir de la cosa pública entendida) se trataran, para defender a advenedizos banqueros cuyo mérito es ser amigo de políticos o a políticos cuyo comportamiento es muy conocido.

3) Adicionalmente, hay que estar prevenido (no sólo en el sentido procesal) y eludir, en la medida de lo posible los fallos(sic) del Tribunal Supremo que son chaqueteros e injustos, al contravenir sentencias que son cosa juzgada por las Audiencias, que afectan a políticos, lo cual es escandaloso porque o falla (en sentido literal) el tribunal inferior o falla (en sentido literal) el tribunal superior. Y, en cualquier caso, falla la administración de justicia.

4) Los jueces deben ser "no partidarios", vale decir "no prevenidos"; y esto viene condicionado por la adscripción de los jueces a organizaciones que se autodenominan "profesionales" que configuran el órgano superior de la judicatura, y trae como consecuencia, resoluciones judiciales parciales, revisables, discutibles, interpretables e injustas.

5) La consideración de algunas personas de carne y hueso, al servicio del estado que son inimputables y la de otros que son aforados es una manifestación fehaciente de que no todos somos "iguales ante la ley"; y esto clama al cielo. Es una contradicción en los términos porque es la propia norma, de obligado cumplimiento (incluso aunque no se conozca) la que establece esas diferencias. Es de vergüenza ajena que un determinado servidor público de la jerarquía y sea cual sea su ámbito: legislativos, ejecutivo y judicial) queden "amparado", vale decir, impune.

6) La legalidad (ilegítima) de la posibilidad de conceder indultos -perdones o eximentes del cumplimiento de sentencias de otro poder -el judicial- por parte de otro poder -el ejecutivocomo mecanismo en manos de los políticos para pagarse "favores" los unos a los otros como lo demuestra el alto nivel de correlación de esas trasgresiones con las que el poder ejecutivo se salta a la torera las resoluciones (sentencias) del poder judicial en particular entre los corruptos (que sólo se encuentran entre los políticos). 
En suma, se consagra el que un poder se inmiscuya en las acciones de otro, con lo que sólo se puede concluir que no son independientes, según el planteamiento clásico de la separación de poderes, y que uno es ascendiente sobre otros.

7) La relación entre fines y medios es muy desigual: la administración de justicia es injusta por su lentitud (hay casos -generalmente de corrupción política- que tardan en se juzgados varios quinquenios). Y, relacionado con esta deficiencia se añade otra deficiencia: se ha aprobado un sistema de tasas que excluye del acceso a la justicia a un gran número de justiciables en determinados supuestos que son de interés para los integrantes de las organizaciones de producción en general y para los de las organizaciones de producción de participación en particular. Y, el argumento ha sido "desatascar" (nótese la inteligencia de la población en el uso del lenguaje) a la justicia.

8) Se tiene la certeza de que las cauciones y multas señaladas a los delincuentes no consiguen satisfacer a los justiciables, particularmente cuando son muchas personas los afectados. Son conocidos los casos de condenados que después de haber pasado en prisión un periodo menor que el establecido en la condena (no se quiere entrar aquí en las cuestiones de vigilancia penitenciaria que son de mucha enjundia) siguen disponiendo de un patrimonio conseguido, al menos, en parte, gracias a los delitos que han sido cosa juzgada, gracias a los alzamientos y fugas.

En suma: si no hay justicia no hay democracia. En efecto: si la democracia se basa en la regla una persona un voto es porque se fundamenta en el principio de que todos los miembros del país (denominación que recibe la sociedad a la que está encaramada -valga la expresión- el estado) son iguales.

La justicia tendría que ser 1) ciega, 2) independiente, 3) igual para todos y además, 4) eficiente. Sin embargo, ninguna de esas condiciones se da en la actualidad con carácter general, como denunció y proclamó hace mucho tiempo el ex alcalde de JÉREZ de la FRONTERA, Pedro PACHECO, en una frase que forma parte del acervo cultural: "la justicia es un cachondeo".

\section{LA ADMINISTRACIÓN}

Se trata de la estructura, dependiente de la organización, formal e informal de unidades funcionales u operativas para desarrollar las tareas productivas y de distribución. 
Evidentemente, su forma, su adecuación, su adaptación, su modo de ser, su manifestación, depende del carácter de la organización de la que depende.

En cualquier caso, la administración no es democrática por su propia esencia, ya que, en cualquiera de sus manifestaciones desarrolla una estructura jerárquica que, para que sea eficiente, requiere disponer de unos canales de comunicación suficientemente fluidos.

\subsection{La imperativa búsqueda de la eficiencia en la ejecución de las tareas}

La organización tiene que ser eficiente independientemente de su sistema de gobierno; y, además, como el desarrollo de muchas tareas no admite más cambios que los que la competitividad reconoce y aconseja, el ejercicio de la regla una persona un voto está muy constreñido en el ámbito de las tareas administrativas que invaden cualquier ámbito del proceso de producción y distribución.

La democracia en las organizaciones no alcanza a todo.

En efecto, ni siquiera en organizaciones que acometen funciones desarrolladas por personas muy homogéneas por su capacidad profesional, nivel de formación, especialización, experiencia y las otras condiciones para desplegar las tareas, ni siquiera en esas organizaciones (por ejemplo, estudios de ingenieros forestales especializados en evaluar el impacto sobre el medio ambiente de las iniciativas humanas o acaso unidades de investigación en biología molecular) es posible desarrollar las funciones democráticamente; ni siquiera es posible aplicar la democracia para decidir quien hace cada tarea.

La causa es la necesaria especialización para conseguir destrezas que favorezcan que la organización sea eficiente.

\subsubsection{La eficiencia se superpone a la democracia}

En realidad el epígrafe está mal enunciado. Se asume, implícitamente, el sentido común, por el cual todos los miembros están de acuerdo en anteponer la búsqueda de la eficiencia (porque conviene a todos, por tanto hay un latente ejercicio de la democracia que llevará a una ausencia de democracia en la ejecución de tareas) en el desarrollo de las tareas, antes que el ejercicio de la democracia hasta para decidir como hacer lo que hay que hacer. 


\subsubsection{LA IMPLANTACIÓN DE ESTRUCTURAS ADMINISTRATIVAS FUNCIONALES, MÁS O MENOS, PARTICIPATIVAS}

Se instalan, en casi todas las organizaciones, por pequeñas que sean, por participativas que sean, por homogéneas que sean, por variadas que sean, estructuras administrativas a través de la que discurren los flujos de información para tomar las decisiones que afectan a la ejecución de las distintas tareas, con el correspondiente riesgo de anquilosamiento, adormecimiento, envejecimiento y de asunción de valores indiscutibles.

En realidad este proceso es muy natural, y aparece constantemente en la naturaleza (que, por cierto, es bastante eficiente pero poco democrática).

\subsubsection{EL DESARROLLO DE LAS FUNCIONES DE LAS UNIDADES ADMINISTRATIVAS DEBIDO A LA NECESARIA ESPECIALIZACIÓN}

Consecuentemente, se produce una falta de democracia en el devenir de la organización, derivada de la necesidad de adoptar e implantar una estructura administrativa que permita coordinar, ordenar temporalmente, y hacer más eficiente, el desarrollo de las funciones debido a la necesaria especialización.

\section{LA DIRECCIÓN DE LA ORGANIZACIÓN}

La dirección o el proceso de consecución de los objetivos establecidos por la estructura de poder que es la organización es una función poco democrática por su complejidad. En efecto, esta importantísima función depende, en cualquier organización, directamente de la propia organización y se configura como un bucle de informacionesdecisiones encadenadas que se suceden sin fin en cualquiera de las manifestaciones de cualquier tipo de organización: producción, distribución, finanzas, etcétera. Incluso es aplicable a cualquier ser con ojos en la cara, capaz de ver "lo que tiene delante".

Es decir, la dirección es una función que se desarrolla a lo largo de un periodo de tiempo.

Los epígrafes que siguen describen los nudos o fases sucesivas o etapas vinculadas que conforman el proceso de dirección de cualquier organización. 


\subsection{El establecimiento y el re-establecimiento de los objetivos}

Este nudo es un dato, que puede plantearse como el dato inicial, aunque haya que volver a él al final del proceso. Se trata de determinar a donde ir, en el bien entendido de que, como consecuencia del proceso de dirección, cabe la posibilidad de cambiar los objetivos: matizarlos, modificarlos o incluso ratificarlos para el siguiente periodo de tiempo.

En este establecimiento de objetivos es la única ocasión en la que los miembros pueden tener la posibilidad de traer a la organización las maneras que teóricamente se desarrollan en la vida civil: una persona un voto; en cuyo caso, la organización es de participación, y si es de producción, se puede hablar de organización de producción de participación.

Pero, incluso en este tipo de organizaciones cabe dirimir si se practica una auténtica democracia debido a la heterogeneidad de los diferentes participantes: proveedores, consumidores, acreedores, trabajadores (que pueden tener diferente vinculación con la organización: asalariados o trabajadores por cuenta propia, e incluso diferentes categorías profesionales).

Un ejemplo puede ilustrar lo manifestado: el caso de un despacho de abogados en el que trabajan los socios y otros que no lo son, incluyendo a otros letrados, que no ejercen la función propia de los colegiados, e incluso otros que, bien desde dentro, como asalariados, o desde fuera, trabajan para prestar servicios profesionales esenciales: la llevanza de la contabilidad, el asesoramiento de la imagen, etcétera.

Así pues, ni siquiera en organizaciones homogéneas, y ni siquiera en esta fase cabe entender que la democracia se puede desarrollar en sentido estricto; y, eso sin contar las consideraciones de más arriba acerca de la sumisión de los votantes a determinadas situaciones naturales de autoridad natural derivada de la antiguiedad, sabiduría, prestigio, influencia o capacidad de conseguir clientela.

En cualquier caso, además, como ya se describe más arriba, hay poco margen de maniobra: quizás la ordenación de causas y efectos (y, subsiguientes causas y efectos) ya que en el árbol de las metas, subobjetivos, objetivos y fines puede haber alguno o algunos grados de libertad. 


\subsection{El diagnóstico}

Los subepígrafes que integran este apartado componen el segundo conjunto de datos para la toma de decisiones que se acumulan a los datos que se han obtenido al establecer los objetivos.

Por tanto, en este proceso no cabe aplicar la regla democrática de una persona un voto.

Lo más que se puede conseguir es una divulgación homogénea, o al menos, una difusión de la información a través de soportes de libre acceso para los integrantes que pueden participar en la toma de decisiones; ya que, de lo contrario, una disposición heterogénea, sólo puede contribuir a una democracia imperfecta e incluso a una situación perfectamente antidemocrática. En efecto, si información es poder, la falta de información y la información parcial sólo puede contribuir a desnaturalizar la toma de decisiones.

\subsubsection{El análisis de las restricciones}

Se trata de la observación, estudio, investigación, evaluación y comparación de las limitaciones con las que se tropieza la organización, que pueden ser internas o externas.

En esta fase la democracia sólo puede ser protegida para eludir los riesgos referidos más arriba.

\subsubsection{ELANÁLISIS DE LAS RESTRICCIONES INTERNAS: LAS DEBILIDADES}

Se refiere a todos los aspectos que, dependiendo de la propia organización, pueden limitar, constreñir, y hacer complejo, e incluso imposible, la consecución de los objetivos que deben ser conocidos y evaluados con el fin de tomar las decisiones oportunas para reducirlos $\mathrm{y}$, a ser posible, eliminarlos.

\subsubsection{EL ANÁLISIS DE LAS RESTRICCIONES: LAS AMENAZAS}

Se refiere a todos los aspectos que, independientes de la propia organización, pueden limitar, constreñir, y hacer complejo, e incluso imposible, la consecución de los objetivos que deben ser conocidos y evaluados con el fin de tomar las decisiones oportunas para reducirlos $\mathrm{y}$, a ser posible, eliminarlos. 


\subsubsection{El análisis de las potencialidades}

Se trata de la observación, estudio, investigación, evaluación y comparación de las capacidades disponibles para la organización, que pueden ser internas o externas.

En esta fase la democracia sólo puede ser protegida para eludir los riesgos referidos más arriba. Y, habida cuenta que las capacidades pueden ser manejables, dentro de un orden, conviene que sean administradas con la diligencia de "un buen padre de familia" utilizando una terminología machista y excluyente del Código Civil que sorprendentemente no se pone en tela de juicio. Por tanto, esa eficiencia que se recomienda exige una profesionalidad que no se compadece, necesariamente, con el ejercicio de la democracia.

\subsubsection{EL ANÁLISIS DE LAS POTENCIALIDADES: LAS FORTALEZAS}

Se refiere a todos los aspectos que, dependiendo de la propia organización, pueden favorecer, ayudar, e incluso hacer más fácil la consecución de los objetivos que deben ser conocidos y evaluados con el fin de tomar las decisiones oportunas para multiplicarlos.

\subsubsection{EL ANÁLISIS DE LAS POTENCIALIDADES: LAS OPORTUNIDADES}

Se refiere a todos los aspectos que, independientes de la propia organización, pueden favorecer, ayudar, e incluso hacer más fácil la consecución de los objetivos que deben ser conocidos y evaluados con el fin de tomar las decisiones oportunas para aprovecharlos.

\subsection{La planificación}

El proceso de concreción de ¿qué hacer? ante cada contingencia para un intervalo de tiempo futuro se conoce como planificación. Por tanto, se trata de una fase en la que hay que elegir, aunque sea ante situaciones que no tienen porque ocurrir.

Se trata, por un lado, de un proceso en el que cabría pensar en aplicar la regla de una persona un voto, ya que hay que elegir entre alternativas, aunque sólo sean, eventuales. Pero, por otro lado, habida cuenta la complejidad de la ordenación y concatenación de decisiones ("una cosa lleva a la otra" y "tiempo al tiempo" siempre que "se esté a lo que se está") se trata de un proceso complejo que requiere aplicar un nivel de conocimientos amplio, incluso en organizaciones sencillas que habitan en entornos no turbulentos, y la administración de la 
información acumulada en el establecimiento de objetivos y en el diagnóstico. Por tanto, el ejercicio de la democracia está también limitado en esta etapa.

Cabe afirmar que la planificación está implícita en toda la naturaleza pero que igual que los ríos siguen su curso, unos caminos que son los naturales, los que mejor se adecuan al equilibrio de todas las fuerzas que intervienen en el proceso y a la aplicación del principio de conservación de la energía, una cosa análoga ocurre con el discurrir de otras organizaciones: ¿Dónde va Vicente? ¡Donde va la gente!, como ocurre con las migraciones de cebras en las llanuras de África Central, o con las organizaciones de producción que están adaptadas a su mercado.

Sólo las organizaciones innovadoras no se conforman, al menos en sus épocas iniciales; y, es precisamente, en estas circunstancias en las que se pueden detectar manifestaciones de ejercicio de democracia entre los participantes iniciadores de la actividad, precisamente a través del impulso que hay que desarrollar para conseguir un futuro deseado y que las circunstancias ayuden.

\subsubsection{La toma de decisiones anticipada}

Este proceso, tomar decisiones anticipadas, requiere una visión de futuro que sólo está desarrollada por los empresarios (no decir emprendedores ni autónomos ni autoempleados) que, incluso dentro de una organización de producción, que puede ser de participación, creen ver como pueden llegar a ser las cosas y, además, quieren que sean como las imaginan, las suponen o las sueñan. Consecuentemente, cuando asumen los riesgos financieros, profesionales, laborales y personales, para tratar de conseguirlas "arman" (como dicen los argentinos) la organización de producción con esa pretensión, y, a veces, lo logran, e incluso, a veces, consiguen cosas que no imaginaron. Pero, también, nuevamente, a veces, fracasan, aunque sería mejor decir que no consiguen los resultados soñados, sino otros que pueden ser desalentadores o defraudadores.

\subsubsection{LA INFORMACIÓN}

La información es, haciendo una analogía, la materia prima del proceso de toma de decisiones: cuanta mejor (no importa la cantidad porque hay que administrarla y eso conlleva costes que deben ser mínimos, sino la calidad) información, el proceso de toma de decisiones tiene más garantías.

REVESCO No 112 - Extraordinario en Homenaje al Profesor Alfonso Carlos MORALES

GUTIÉRREZ - ISSN: 1885-8031 - www.ucm.es/info/revesco 
Los periodistas de los medios divulgan de oído y lógicamente, mediatizados por la necesidad de contribuir a la supervivencia del medio que les contrata, muchas verdades a medias. En general, hablan de oídas porque se caracterizan por ser aprendices de todo y maestros de nada, ya que su función es "ser testigos de la actualidad", así, entre comillas, aunque, en realidad todos podemos serlo, pero ellos lo son "profesionalmente". Además, en esa importante tarea de divulgar las noticias (cuya categoría admite una valoración) se deberían ver condicionados por un escrupuloso uso del idioma, $\mathrm{y}$, sin embargo, en muchas ocasiones se hacen eco de barbaridades como "condicionalidad", la marca España, "a nivel de Europa" y otras horteradas que se les ocurre a los políticos más incultos, y las propagan sin ningún problema, y lo que es peor, sin conciencia de que están cometiendo errores que afectan al lenguaje: la concreción de lo que nos hace diferentes de los otros animales y nos convierte en ¿racionales?

En el ámbito de la organización de producción es muy sencillo instalar sistemas de procesamiento de la información muy eficientes a los que adaptarse rápidamente favorecido por el enorme interés que tienen los participantes en disponer de toda la información. Los murales virtuales, las redes sociales, los grupos de interés, y otros procedimientos, son mecanismos que permiten que la información fluya con fluidez en el grupo de personas que han de tomar decisiones, ya que a estos soportes de información pueden acceder todos los que son testigos de la realidad: los profesionales y los no profesionales, afortunadamente.

Como se trata en el apartado sobre el valor de la organización, si se informara de las relaciones causales entre fines y medios, de las relaciones encadenadas entre tareas, funciones, metas, objetivos y fines, las decisiones -democráticas- estarían encarriladas con muy poco margen de actuación de manera que la participación en las decisiones, que configura el carácter democrático de la organización, quedaría circunscrita a un abanico de posibilidades muy estrecho.

\subsubsection{La confección de presupuestos}

Se trata de la concreción en términos de unidades monetarias de lo que está recogido en el plan. Por tanto, es un proceso que implica la ejecución de la función siempre complicada de la valoración ("quien parte y reparte se lleva la mejor parte"), y, lo que es más difícil aún, la valoración de cosas que aún no existen, pero se prevé que existirán, aparecerán, se producirán.

REVESCO No 112 - Extraordinario en Homenaje al Profesor Alfonso Carlos MORALES

GUTIÉRREZ - ISSN: 1885-8031 - www.ucm.es/info/revesco 
Aunque la llevanza de las cuentas se puede hacer aplicando la regla de "la cuenta de la vieja", que es el sistema que utilizan algunos tesoreros de algunos partidos políticos que desconocen el citerior de devengo y usan el criterio de caja, lo cierto es que la confección de presupuestos es una función compleja que requiere la aplicación de un conjunto de hipótesis de sentido común, por un lado, y de unas técnicas de llevanza de la contabilidad, que, aunque no son muy complicadas exigen un determinado nivel de conocimientos no disponible por la generalidad.

Por tanto, esta tarea, que es básicamente técnica, no puede ser democrática, sino que ha de ser desarrollada por especialistas tan objetivamente como sea posible.

\subsection{La gestión de las decisiones tomadas desde la Administración}

La ejecución (no usar implementación porque es un solecismo injustificado e injustificable como lo califica María MOLINER) de las decisiones a medida que van llegando el momento en que las funciones del plan han de ser desarrolladas depende de la Administración, que como se ha comentado, depende de la Organización o Estructura de Poder. Una analogía es la de "abrir el melón” y disponerlo para consumirlo.

Ahora bien, como hay una dependencia entre estructura y funciones, según como sea la organización así es la administración y, consecuentemente la gestión. El melón se puede abrir transversalmente o cortarlo por la mitad; y, en ambos casos, se puede trocear (para prepararlo para ser consumido) de varias formas: con una herramienta que extrae los trozos en forma esféricas o bien en rodajas o, incluso en dados.

Dicho de otro modo: los márgenes de maniobra de las propias ejecuciones, cuando los hay, permiten desarrollar una determinada capacidad de tomar decisiones entre los participantes en la ejecución de decisiones, si hay más de uno. De manera que, aunque la organización de producción no sea de participación, puede darse el caso de que haya participación democrática en las decisiones de ejecución por parte de los participantes en esas tareas concretas.

\subsubsection{La obtención de los resultados}

Esta etapa del proceso de dirección resulta de la conjunción de la planificación, a medida que su calendario va aconteciendo, y de la gestión de las decisiones correspondientes. 
Es una función automática.

\subsection{El control de los resultados}

Finalmente es necesario y conveniente desarrollar una última fase del proceso de dirección previa a la del establecimiento (en realidad hay que hablar de re-establecimiento) de los objetivos.

El control es una fase de confección de información. La que resulta de comparar los objetivos perseguidos y establecidos al principio del proceso de dirección que acaba de concluir con los resultados obtenidos.

Este mismo proceso conlleva un requerimiento que debería haber sido atendido con la confección de presupuestos: la necesidad de medir tan concretamente como es posible. Ahora bien, para poder hacer esa comparación adecuadamente, es necesario que los términos a comparar hayan sido evaluados con el mismo criterio y que tengan la misma unidad de medida; y eso lo proporciona la conversión en unidades monetarias, aunque eso conlleve aplicar el complejo y discutible proceso de valoración.

Pero no basta con esa comparación: es necesario y conveniente acumular otra información, que es más compleja de obtener: la que resulta de indagar, escrutar, averiguar y analizar las causas de las diferencias o no entre lo deseado y lo obtenido. Puede ocurrir que aparentemente se ha conseguido batir el objetivo de incrementar las ventas (incluso se conoce que la diferencia es de 2 puntos), pero es necesario comprobar si el objetivo estaba bien establecido o era poco ambicioso.

Por tanto, esta fase de control, es la antesala de la del restablecimiento de los objetivos en donde, nuevamente, hay la posibilidad (ciertamente limitada) de participar en su fijación, a través de los órganos que la organización se de a sí misma.

\section{CONCLUSIÓN}

De manera análoga a como los ciudadanos integramos los denominados estados de derecho (que algunos titulan de desecho) y tenemos la facultad de participar, en teoría, de manera equilibrada en los tres poderes: legislativo, ejecutivo y judicial, lo cierto es que cualquier ciudadano puede participar en realidad sólo en dos de los tres poderes, mientras que 
para participar en el poder judicial hay que ser licenciado en Derecho y miembro de la carrera judicial.

Por su parte, en el seno de las organizaciones de producción el ejercicio de la democracia está también limitado, pero de manera distinta.

El poder legislativo es un dato del problema: el mercado impone sus leyes, aunque cabe una tergiversación (nadar y guardar la ropa) a través de los fenómenos de competencia y cooperación, emulando lo que ocurre con tanta frecuencia en la naturaleza, siquiera para compensar el comportamiento carroñero de los poderes públicos que aparentemente regulan el mercado.

Por su parte, precisamente por los condicionamientos técnicos y la disponibilidad de información, así como por la asunción de que hay más coincidencias en los objetivos que conflictos (precisamente en hacer tan grande como sea posible el valor de la organización), la toma de decisiones bajo la regla de una persona un voto puede estar reconocida y desarrollada a través de órganos, pero está constreñida a lo largo de todo el proceso de dirección o de consecución de los objetivos.

Sin embargo, el poder judicial, aunque es mejor decir, de administración de justicia en los conflictos de competencia y de retribución, en el seno de la organización pueden ser ejercida en la propia organización (los trapos sucios hay que lavarlos en casa) a través de procedimientos que no pasen por la justicia ordinaria(sic) mediante los sistemas de arbitraje y de transición ("más vale un mal pacto que un buen pleito") y el uso de jurados que aplicando subsidiariamente normas y, sobre todo, el sentido común, den a cada uno lo suyo. Y esta capacidad de administrar la justicia en los órdenes civil y mercantil, en lo interno, está legitimada, precisamente por el ejercicio de la democracia por el cual todos somos iguales ante la ley natural; pero, además, porque la administración de justicia convencional "no es de fiar". 